\title{
PASCAL laser platform produces less pain responses compared to conventional laser system during the panretinal photocoagulation: a randomized clinical trial
}

\author{
Sibel Inan ${ }^{1}$, Onur Polat ${ }^{2}$, Safiye Yigit ${ }^{3}$, Umit Ubeyt Inan ${ }^{4}$
}

1. Department of Ophthalmology, Afyon Kocatepe University, Faculty of Medicine, Afyonkarahisar,Turkey.

2. Ophthalmology Clinic, Afyonkarahisar State Hospital, Afyonkarahisar,Turkey.

3. Ophthalmology Clinic, Gerede State Hospital, Bolu,Turkey.

4. Private Office, Ophthalmology, Afyonkarahisar, Turkey.

\section{Emails:}

Sibel Inan,drinan33@gmail.com; Onur Polat, dr_onurpolatt@hotmail.com; Safiye Y1g1t, safiyeyigit87@hotmail.com; Umit Ubeyt Inan, uinan@gmail.com

\begin{abstract}
Background: Most of patients experience pain during the panretinal photocoagulation(PRP). Laser photocoagulation delivery has advanced with the introduction of pattern-scanning laser systems (PASCAL). Shorter pulse duration and less choroidal penetration believed to reduce pain during the laser treatment.

Objectives: To compare the severity of expressed pain scores in patients with PDR who underwent PRP either with PASCAL laser or conventional laser.

Methods: A total of 28 patients with a diagnosis of PDR who were scheduled for bilateral PRP therapy were enrolled into the prospective study. Both eyes were treated within the same session and while one eye was treated with PASCAL the other was treated with conventional laser randomly. Pulse duration was adjusted to 100-ms in conventional laser and $30 \mathrm{~ms}$ in PASCAL. The severity of pain was graded using a verbal scale and a visual analog scale (VAS).

Results: Mean age was $61.36 \pm 9.10$ years. Mean verbal and VAS scores were $1.32 \pm 0.47$ and $2.86 \pm 1.21$ in the PASCAL laser and $2.39 \pm 0.49$ and $5.75 \pm 1.35$ in the conventional laser group, respectively. Differences between expressed pain scores obtained by both two scales were statistically significant $(\mathrm{p}<0.001)$.

Conclusion: PASCAL laser significantly alleviates pain levels possibly due to the shorter laser pulse duration and lower intensity. Keywords: Panretinal photocoagulation, PASCAL, pain.

DOI: https://dx.doi.org/10.4314/ahs.v18i4.22

Cite as: Inan S, Polat O, Ygit S, Inan UU. PASCAL laser platform produces less pain responses compared to conventional laser system during the panretinal photocoagulation: a randomized clinical trial. Afri Health Sci. 2018;18(4): 1010-1017. https:/ / dx.doi.org/10.4314/ahs.v18i4.22
\end{abstract}

\section{Introduction}

Proliferative diabetic retinopathy (PDR) is a severe complication of diabetes mellitus characterized by new ves-
Corresponding author:
Onur Polat,
Afyonkarahisar State Hospital,
Ophthalmology Clinic
03100 Afyonkarahisar, Turkey
Contact phone number: +90542 2704246
Fax number: 0272-2722140600
E-mail: dr_onurpolatt@hotmail.com

sel formation in the retina and optic disc. Tight glycemic control and laser treatment in the early phases of the disease may slow the progression of PDR. ${ }^{1-3}$ Panretinal photocoagulation (PRP) is a laser-based treatment modality that destroys the outer retina layers and thereby improves the oxygen supply of the inner retina. During the following years, sequential improvements took place, including introduction of yellow, green, and diode lasers with various advantages of each wavelength. ${ }^{4}$

In 2006, a novel semi-automatic and multi-shot photocoagulator called as PASCAL (Pattern scan laser, Opti-Medica Corp., Santa Clara, California, USA) was introduced

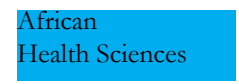

(C) 2018 Inan et al. Licensee African Health Sciences. This is an Open Access article distributed under the terms of the Creative commons Attribution License (https://creativecommons.org/licenses/BY/4.0), which permits unrestricted use, distribution, and reproduction in any medium, provided the original work is properly cited. 
with a reduction in pulse duration of each laser spot from typical $100 \mathrm{~ms}$ down to 10-30 millisecond. Compared with the conventional laser, shorter pulses have been shown to significantly reduce the risk of damage to the adjacent retinal tissues. ${ }^{5,6}$

Almost all patients experience pain during PRP. While some patients may tolerate the pain, the majority does not. $^{7}$ One study reported that $64.1 \%$ of patients did not complete treatment due to pain and therefore had an increased risk of vision loss. ${ }^{8}$ To improve patient compliance, several anesthetic and analgesic techniques such as peribulbar anesthesia, oral anesthesia and topical eye drops have been used. ${ }^{9-11}$ The patient comfort, and thus compliance, may be improved by using the shorter exposure burns, avoiding red or infrared wavelengths with deeper penetration, and by decreasing overall treatment time.

In the current study we aimed to compare the severity of expressed pain scores in patients with PDR who underwent either PASCAL or conventional laser. Additionally we assessed the association between patient characteristics and severity of pain.

\section{Methods}

This prospective study included a total of 28 patients with a diagnosis of PDR who were scheduled for bilateral PRP therapy. Inclusion criteria comprised patients (>18 years) with type 1 or 2 diabetes and bilateral highrisk proliferative diabetic retinopathy (PDR), which was defined as the presence of neovascularization (NVD) at the disc, presence of NVD associated with vitreous or preretinal hemorrhage, or neovascularization elsewhere of more than half the disc area associated with vitreous or preretinal hemorrhage.
Patients with a history of focal/grid photocoagulation, a history of orbital trauma, orbital infection or surgery, those with corneal or lens opacities, those with vitreous hemorrhage and non-compliant patients were excluded from the study. This study was conducted in accordance with tenets of the Declaration of Helsinki and institutional review board approval was obtained from Local Ethics Committee. Informed consent was obtained from all participants. The name of the registry and the registration number is ClinicalTrials.gov, ID: NCT02645383. All participants underwent comprehensive ophthalmic examinations, including visual acuity testing, slit-lamp biomicroscopy, intraocular pressure measurement using Goldmann applanation tonometer, and dilated fundoscopic examination. Color fundus photographs and fluorescein angiography were performed at baseline before laser photocoagulation.

We usually finish the full PRP of one eye in four session. One of these sessions was used for this study. Due to study circumstances, the session that was be used for this study was not prolonged and the session was completed in a shorter duration than the others to keep both eyes of the patient under the treatment in this session. Therefore the number of laser shots was less than in the usual PRP session. Consequently, both eyes were treated within the same session and while one eye was treated with PASCAL laser, the other was treated with conventional laser (ELLEX Integre, Adailade, Australia) with 30 minutes resting intervals. To avoid a bias about orientation or becoming accustomed to laser procedure, PASCAL laser was performed in the first eyes in half of the patients (14 patients) and conventional laser was performed in the first eyes in the other half of the patients randomly (Figure 1). 


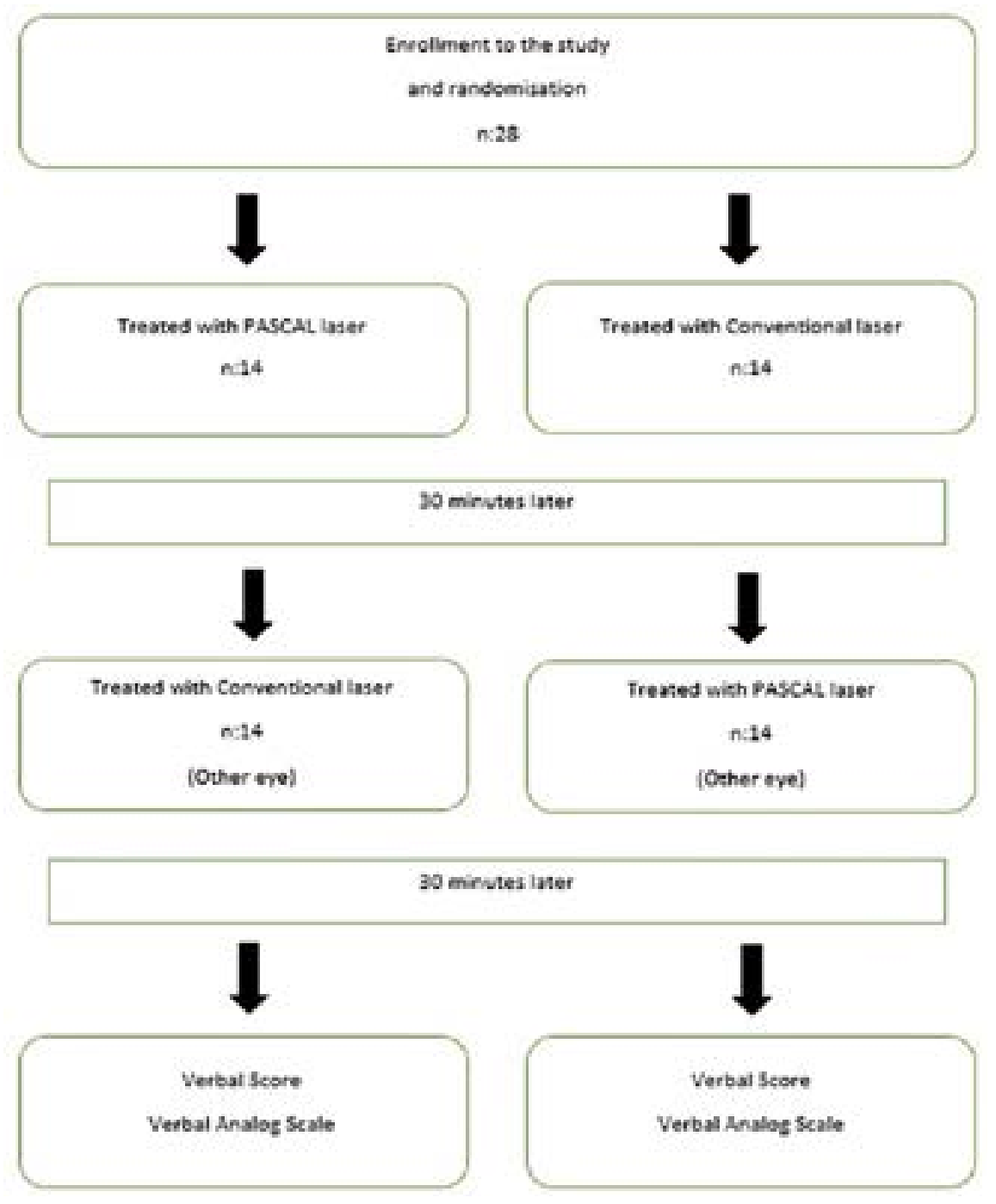

Figure 1: Participant flow through study

While the spot size used to obtain a white-grayish spot on the retina was $200-400 \mu \mathrm{m}$ in both PASCAL and conventional laser, the pulse duration was $100 \mathrm{~ms}$ with conventional laser and 30ms with PASCAL laser. In order to accurately and reliable compare the grade of pain between each procedures, we tried to standardize the retinal areas and total number of spots delivered. Similar numbers of laser spots were created by two laser systems in similar retinal quadrants in both eyes. Thirty minutes after the procedure ended the severity of pain was assessed using a verbal rating scale and a visual analog scale (VAS). In the verbal scale the patient rates the pain on a Likert scale verbally, e.g. "none", "mild pain", "moderate pain", "severe pain" or "very severe pain" in five grading system $(0-4)$ and in the VAS they specify the severity of pain by indicating a position along a continuous line from 0 to 10 (Figure 2).

A

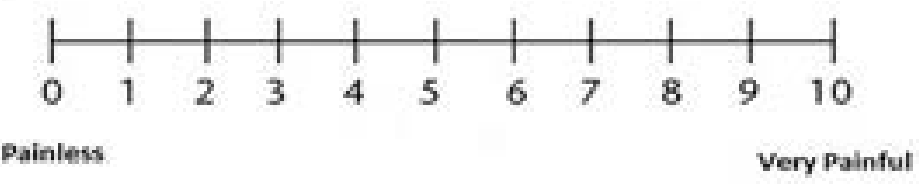

B

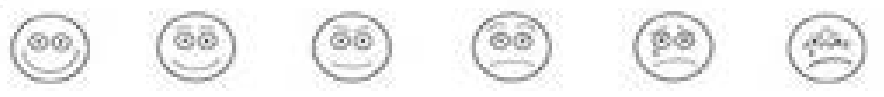

Figure 2: Visual Analog Scale 
Using these scores we assessed the relationship between severity of pain and patient characteristics including history of prior PRP treatment (experience), gender and duration of diabetes mellitus. Patients were assigned either in the experienced or non-experienced groups depending on history of prior PRP. The person who performed the VS and VAS tests was blinded for the laser machine used in each eye.

Statistical analyses were performed using the SPSS (Statistical Package for Social Sciences Inc., Chicago, IL, ABD) 17.0 software. Distribution of data was assessed by the Shapiro-Wilk test. Comparison was undertaken using the Mann-Whitney $U$ test. The minimal significance $(\alpha)$ and statistical power $(1-\beta)$ were set at 0.05 and 0.80 respectively.

\section{Results}

Mean age was $61.36 \pm 9.10$ years and mean diabetes duration was $9.84 \pm 6.96$ (minimum 0.25 - maximum 27.5) years. The mean number of laser spots delivered did not significantly differ between the PASCAL and conventional laser groups (435.36 \pm 77.46 vs. $436.18 \pm 74.63$; $\mathrm{p}=0.76)$. The mean PRP duration was significantly shorter in the PASCAL vs. conventional laser group (3.76 $\pm 0.48 \mathrm{~min}$ vs. $6.65 \pm 0.98$ min; $\mathrm{p}<0.001)$.

Mean verbal and VAS scores were $1.32 \pm 0.47$ and $2.86 \pm 1.21$ in the PASCAL laser and 2.39 \pm 0.49 and $5.75 \pm 1.35$ in the conventional laser group, respectively. Pain scores obtained from both assessments were significantly lower in patients in the PASCAL group $(\mathrm{p}<0.001)$ (Table 1).

\section{Table 1: Pain scores in patients}

\begin{tabular}{llll}
\hline & PASCAL & $\begin{array}{l}\text { Conventional } \\
\mathrm{n}=16\end{array}$ & $p$ \\
\hline Verbal Score & $1.32 \pm 0.47$ & $2.39 \pm 0.49$ & $<0.001$ \\
VAS & $2.86 \pm 1.21$ & $5.75 \pm 1.35$ & $<0.001$ \\
\hline
\end{tabular}

VAS: Visual Analog Scale; p:Mann-Whitney U test

Number of experienced vs. non-experienced patients was 17 (\%60.7) and 11 (\%39.3), respectively. Mean verbal and VAS scores were both significantly lower in experienced vs. non-experienced patients in the PASCAL group $[(1.12 \pm 0.33)$ and $(2.35 \pm 0.93)$ vs. $(1.64 \pm 0.5)$ and (3.64 \pm 1.21$)$; (p: 0.005 and 0.009 , respectively)] as well as in the conventional laser group $[(2.24 \pm 0.44)$ and

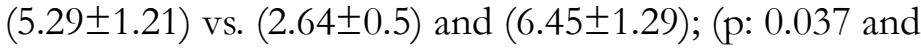
0.027, respectively)] (Figure 3).

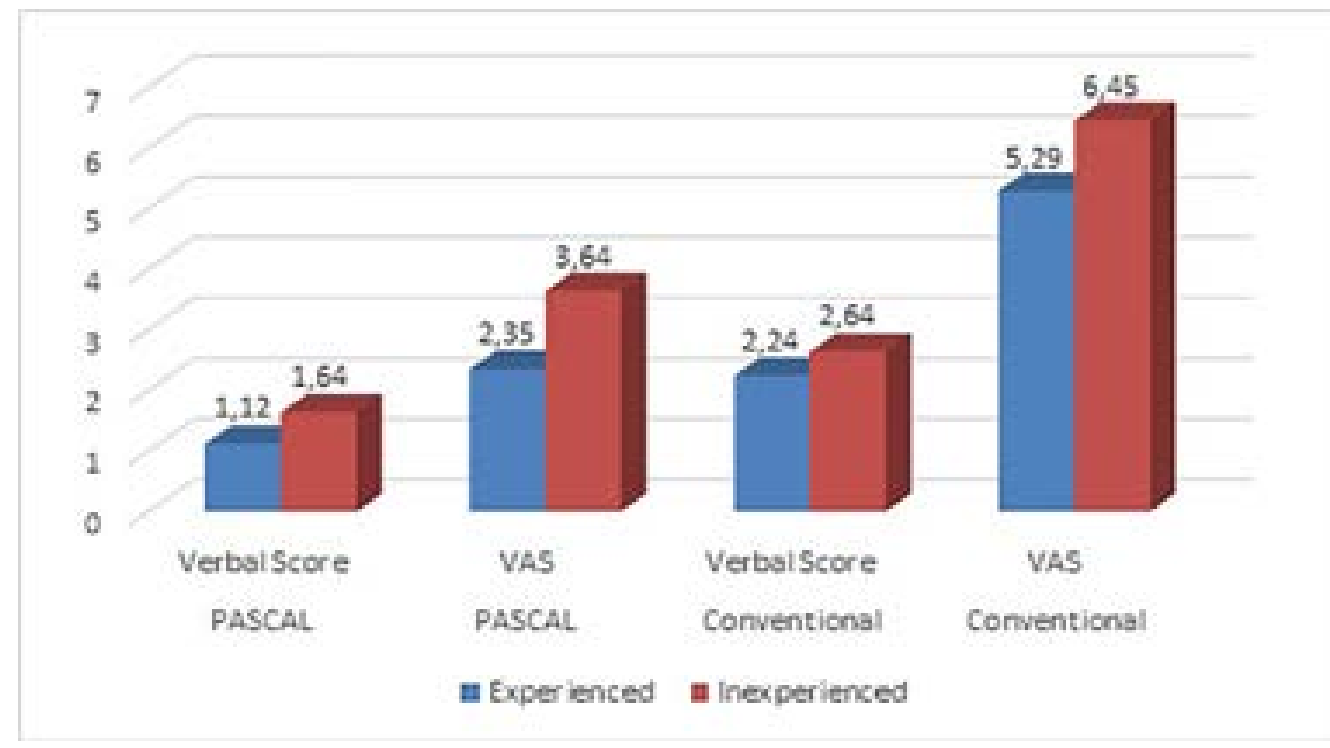

Figure 3: Pain scores in experience and inexperienced patients on previous laser treatments; VAS: Visual Analog Scale 
Of the enrolled patients 12 (42.9\%) were females and 16 $(57.1 \%)$ males. While female patients scored higher for verbal scale and VAS in each of the PASCAL and con- ventional laser groups, the difference reached statistical significance only in the PASCAL group (p: 0.08 and 0.02, respectively) (Table 2 ).

Table 2: Pain scores according to gender

\begin{tabular}{llll}
\hline & $\begin{array}{l}\text { Female } \\
\mathrm{n}=12\end{array}$ & $\begin{array}{l}\text { Male } \\
\mathrm{n}=16\end{array}$ & $p$ \\
\hline PASCAL-Verbal Score & $1.50 \pm 0.52$ & $1.19 \pm 0.40$ & 0.08 \\
Conventional-Verbal & $2.42 \pm 0.51$ & $2.38 \pm 0.50$ & 0.83 \\
Score & & & \\
PASCAL-VAS & $3.50 \pm 1.69$ & $2.38 \pm 1.02$ & 0.02 \\
Conventional-VAS & $5.92 \pm 1.44$ & $5.63 \pm 1.31$ & 0.59 \\
\hline
\end{tabular}

VAS: Visual Analog Scale; p:Mann-Whitney U test

In the conventional laser group, patients with diabetes duration longer than 120 months had significantly lower verbal scale and VAS pain scores than those with diabe- tes duration less than 120 months (p:0. 003 and 0.001, respectively). In the PASCAL group, however, the difference was not significant (Table 3).

Table 3: Pain scores according to duration of DM

\begin{tabular}{llll}
\hline & $\begin{array}{l}\mathrm{DM} \leq 120 \text { months } \\
\mathrm{n}=13\end{array}$ & $\begin{array}{l}\mathrm{DM}>120 \text { months } \\
\mathrm{n}=15\end{array}$ & $p$ \\
\hline PASCAL-Verbal Score & $1.31 \pm 0.48$ & $1.33 \pm 0.49$ & 0.889 \\
Conventional-Verbal & $2.69 \pm 0.48$ & $2.13 \pm 0.35$ & 0.003 \\
Score & & & \\
PASCAL-VAS & $3.08 \pm 1.12$ & $2.67 \pm 1.29$ & 0.365 \\
Conventional-VAS & $6.69 \pm 1.25$ & $4.93 \pm 0.79$ & 0.001 \\
\hline
\end{tabular}

GAS: Visual Analog Scale; DM: Diabetes Mellitus; p:Mann-Whitney U test

Correlation analysis revealed significant correlation between verbal scores and history of laser photocoagulation (LFC) and number of burns, as well as between VAS scores and gender, history of LFC and number of burns in the PASCAL group $(\mathrm{r}=-0.542, \mathrm{p}=0.003, \mathrm{r}=0.453, \mathrm{p}=0.015 \mathrm{r}=$ $0.469, \mathrm{p}=0.012, \mathrm{r}=-0.528, \mathrm{p}=0.004, \mathrm{r}=0.533, \mathrm{p}=0.004$, respectively). Similarly significant correlation was observed between both verbal and VAS scores and duration of $\mathrm{DM}$, history of LFC and number of burns in the conventional laser group $(\mathrm{r}=-0.500, \mathrm{p}=0.007, \mathrm{r}=-0.401, \mathrm{p}=0.034$, $\mathrm{r}=0.514, \mathrm{p}=0.005 \mathrm{r}=-0.469, \mathrm{p}=0.012, \mathrm{r}=-0.427, \mathrm{p}=0.023$, $\mathrm{r}=0.518, \mathrm{p}=0.005$, respectively).

\section{Discussion}

In our study, PASCAL laser platforms showed signifi- cantly less laser-induced pain compared to conventional diode pumped laser system in patients with PDR in a setting of bilateral, crossover, limited PRP study design. It is well recognized that PRP treatment decreases the risk of vision loss in patients with severe PDR. ${ }^{12}$ Appropriate medical treatment and clinical follow-up may reduce the risk of diabetes related vision loss by $90 \% .{ }^{13}$ PRP may be significantly painful and may cause discomfort in some patients and it may, therefore, be interrupted due to intolerance to pain. Consequently, patients experiencing pain in the first PRP session may miss the next due to the fear of recurrence of the same pain. By altering some laser parameters, e.g. duration of laser pulse, however, thistreatment modality may prove more comfortable and less painful. ${ }^{14}$ But, very short pulse durations in conventional single spot lasers, may causes ineffective spots.

African Health Sciences Vol 18 Issue 4, December, 2018 
Although same retinal quadrants were treated and the mean number of laser pulses delivered did not significantly differ between two groups, verbal and VAS pain scores were significantly lower in patients in the PASCAL laser than in the conventional laser group. We consider that this difference probably was due to a shorter laser pulse as well as different laser technology in the PASCAL platform.

The thermal energy produced during PRP may, depending on the duration of the procedure, cause collateral damage to adjacent tissues. Long pulse duration used during conventional laser application (100-200 ms) may cause larger scars in the retinal tissue and thereby may increase retinal pigment epithelium (RPE) damage. ${ }^{15,16}$ The PASCAL laser technique uses shorter pulses as compared with conventional laser. It is possible that decreasing the pulse duration from mili- to microseconds alleviates pain. Targeting the retinal pigment epithelium while preserving adjacent photoreceptors through micro-air bubble formation formed around melanosomes is a novel target therapy modality of laser photocoagulation. The critical threshold between thermal and mechanical damage is 50 ms. ${ }^{17-19}$ In conventional lasers, it is not possible to use shorter pulse duration shorter than $100 \mathrm{~ms}$ in 200 micron or larger shots. Shorter pulses used during PASCAL laser cause mechanical rupture but not thermal damage, due to the formation of transient vapor bubbles. The damage is thereby, limited to the retinal pigment epithelium and outer retinal layers and does not extend to the inner retinal layers and sensory-rich chorioretinal tissues. This condition has the potential to decrease pain because both vertical and axial scaring will decrease and hence will limit collateral damage to the retina and increase preservation of retinal sensitivity. ${ }^{20}$

A recent study reported that the total time of PRP duration was significantly shorter with PASCAL laser than with conventional laser. ${ }^{21}$ Our results confirmed this finding. Shortening of the total time is also critical in that it may increase compliance due to pain relief.

Long laser pulse duration in conventional laser is associated with more severe pain and increased rate of photophobia following laser therapy. Local ocular inflammatory response may increase retinal neurogenic inflammation in pain transmitting nerve cells and thereby may increase the intensity of pain. Muqit et al. ${ }^{22}$ reported that intraretinal inflammation and the severity of pain was higher in patients who were treated with $100 \mathrm{~ms}$ single spot conventional laser as compared with 20 ms multi-spot PASCAL laser.

One may be concerned that while shorter duration of laser pulse with PASCAL laser alleviates pain, it may also cause under treatment. Studies from the literature, however, have consistently shown that treatment efficacy was similar between PASCAL and conventional laser treatment. ${ }^{20,23}$

The perception of pain during PRP may vary from patient to patient and it may be influenced by many factors such as the pain threshold, cultural differences, degree of fundus pigmentation, history of prior laser treatment, anxiety and gender. ${ }^{20}$ In the current study, mean verbal and VAS scores were significantly lower in experienced vs. non-experienced patients in both the PASCAL and conventional laser groups, confirming that experience is an important factor associated with post-operative pain.

Several studies reported that the threshold of pain was lower in women. ${ }^{24}$ In addition, it was detected that retinal thickness is thinner in women than in men. Some ocular distinctions between men and women such as retinal and choroidal thickness, ocular blood flow and hormonal differences may be related to pain score differences. ${ }^{25,26}$ In the current study we found a significant relationship between gender and the severity of pain in the PASCAL group and also between diabetes duration and severity of pain in the conventional laser group. It is well recognized that patients with diabetes may experience silent myocardial infarction due to the damage occurring on the sensory fibers implicated in pain processing. ${ }^{27}$ A similar pathway may have caused damage to the retinal pain neurons and therefore patients with longer duration of diabetes may have felt less intense pain. Additionally, the fact that pain perception is a subjective and personal experience, sociocultural differences may, in part, have accounted for the difference in the perception of pain reported among individuals.

The limitations of our current study include the small patient series and while the relatively small number of spots delivered may appear to be a limitation, the main purpose 
of the study was to compare pain responses and not to compare treatment efficacy. Additionally, we followed all patients and performed the second to fourth treatment sessions after one week at the latest and eventually completed PRP treatments within one month.

\section{Conclusion}

Due to shorter laser pulse and lower intensity or the different technology used, PASCAL platform provides significant alleviation of pain during PRP and, therefore, may increase compliance.

The name of the registry and the registration number is ClinicalTrials.gov, ID: NCT02645383.

This study was presented at $48^{\text {th }}$ TOD National Congress, 5-9 November 2014, Antalya,Turkey.

\section{Conflict of interest}

No conflict of interest is declared by the authors.

\section{Financial disclosure}

The authors declared that this study received no financial support.

\section{References}

1. Aiello LP, Gardner TW, King GL, Blankenship G, Cavallerano JD, Ferris FL 3rd et al. Diabetic retinopathy. $D i$ abetes Care. 1998; 21 (1): 143-56. PubMed.

2. American Diabetes Association. Diabetic retinopathy. Position statement. Diabetes Care. 1998; 21 (1): 157-9. PubMed.

3. Feman SS, Chen J, Burroughs TE. Change in Diabetic Panretinal Photocoagulation Incidence. Ophthalmic Surg Lasers Imaging. 2012; 43 (4): 270-4

4. Krauss JM, Puliafito CA. Lasers in ophthalmology. Lasers Surg Med. 1995; 17 (2): 102-59. PubMed.

5. Jain A, Blumenkranz MS, Paulus Y, Wiltberger MW, Andersen DE, Huie P et al. Effect of pulse duration on size and character of the lesion in retinal photocoagulation. Arch Ophthalmol. 2008; 126(1): 78-85. PubMed.

6. Blumenkranz MS, Yellachich D, Andersen DA, Wiltberger MW, Mordaunt D, Marcellino GR et al. Semiautomated patterned scanning laser for retinal photocoagulatiom. Retina. 2006; 26 (3): 370-6. PubMed.

7. Zakrzewski PA, O’Donnell HL, Lam WC. Oral versus topical diclofenac for pain prevention during panretinal photocoagulation. Ophthalmology. 2009; 116: 1168-744
8. Bailey CC, Sparrow JM, Grey RH, Cheng H. The National Diabetic Retinopathy Laser Treatment Audit. II. Proliferative retinopathy. Eye. 1998; 12 (Pt 1): 77-84

9. Wu WC, Hsu KH, Chen TL, Hwang YS, Lin KK, Li $\mathrm{LM}$ et al. Interventions for relieving pain associated with panretinal photocoagulation: a prospective randomized trial. Eye. 2006; 20(6): 712-9. PubMed.

10. Vaideanu D, Taylor P, McAndrew P, Hildreth A, Deady JP, Steel DH. Double masked randomised controlled trial to assess the effectiveness of paracetamol in reducing pain in panretinal photocoagulation. $\mathrm{Br} J \mathrm{Oph}$ thalmol. 2006; 90 (6): 713-7. PubMed.

11. Weinberger D, Ron Y, Lichter H, Rosenblat I, Axer-Siegel R, Yassur Y. Analgesic effect of topical sodium diclofenac $0.1 \%$ drops during retinal laser photocoagulation. Br J Ophthalmol. 2000; 84(2): 135-7. PubMed.

12. Photocoagulation for diabetic macular edema. Early Treatment Diabetic Retinopathy Study Report Number 1.Early Treatment of Diabetic Retinopathy Study. Arch Ophthalmol. 1985; 103 (12) :1796-806. PubMed.

13. Ferris FL.: How effective are treatments for diabetic retinopathy. JAMA. 1993; 269 (10): 1290-1. PubMed.

14. Alvarez-Verduzco O, Garcia-Aguirre G, Lopez-Ramos Mde L, Vera-Rodriguez S, Guerrero-Naranjo JL, Morales-Canton V. Reduction of Fluence to Decrease Pain During Panretinal Photocoagulation in Diabetic Patients. Ophthalmic Surg Lasers Imaging. 2010; 41 (4): 432-6

15. Schatz H, Madeira D, McDonald HR, Johnson RN. Progressive enlargement of laser scars following grid laser photocoagula $\neg$ tion for diffuse diabetic macular edema. Arch Ophthalmol. 1991; 109 (11): 1549-51. PubMed. 16. Hudson C, Flanagan JG, Turner GS, Chan HC, Young LB, Mcleod D. Influence of laser photocoagulation forclinically significant macular oedema on shortwawelength and conventional automated perimetry. Diabetologica. 1998; 41 (11): 1283-92. PubMed.

17. Schuele G, Rumohr M, Huettmann G, Brinkmann R. RPE damage thresholds and mechanisms for laser exposure in the microsecond-to-millisecond time regimen. Invest Ophthalmol Vis Sci. 2005; 46 (2): 714-9

18. Mainster M. Decreasing retinal photocoagulation damage: principles and techniques. Semin Ophthalmol. 1999; 14 (4): 200-9. PubMed.

19. Luttrull JK, Musch DC, Spink CA. Subthreshold diode micropulse panretinal photocoagulation for proliferative diabetic retinopathy. Eye. 2008; 22 (5): 607-12. PubMed. 20. Al-Hussainy S, Dodson PM, Gibson JM. Pain response and follow-up of patients undergoing panretinal African Health Sciences Vol 18 Issue 4, December, 2018 
laser photocoagulation with reduced exposure times. Eye. 2008; 22 (1): 96-9. PubMed.

21. Nagpal M, Marlecha S, Nagpal K. Comparison of laser photocoagulation for diabetic retinopathy using 532$\mathrm{nm}$ Standard laser versus multispot pattern scan laser. Retina. 2010; 30(3): 452-8. PubMed.

22. Muqit MM, Marcellino GR, Gray JC, McLauchlan R, Henson DB, Young LB et al. Pain responses of Pascal 20 ms multi-spot and $100 \mathrm{~ms}$ single-spot panretinal photocoagulation: Manchester Pascal Study, MAPASS report 2. Br J Ophthalmol. 2010; 94 (11): 1493-8. PubMed.

23. Mirshahi A, Lashay A, Roozbahani M, Fard MA, Molaie S, Mireshqhi M et al. Pain score of patients undergoing single spot, short pulse laser versus conventional laser for diabetic retinopathy. Graefes Arch Clin Exp Ophthalmol. 2013; 251 (4): 1103-7

24. Fillingim RB. Sex, gender, and pain: women and men really are different. Curr Rev Pain. 2000; 4 (1): 24-30. PubMed.

25. Eisner A. Sex, eyes, and vision: male/female distinctions in ophthalmic disorders. Curr Eye Res. 2015; 40 (2): 96-101

26. Ooto S, Hangai M, Yoshimura N. Effects of sex and age on the normal retinal and choroidal structures on optical coherence tomography. Curr Eye Res. 2015; 40 (2): 213-25

27. Manzella D, Paolisso G. Cardiac autonomic activity and Type II diabetes mellitus. Clin Sci. 2005; 108 (2): 93-9. PubMed. 